\title{
Dynamics of a fault model with two mechanically different regions
}

\author{
Michele Dragoni(D) and Emanuele Lorenzano * (1)
}

\begin{abstract}
We consider a fault containing two regions with different mechanical behaviours: a strong, velocity-weakening region (asperity) and a weak, velocity-strengthening region. The fault is embedded in a shear zone subject to a constant strain rate by the motions of adjacent tectonic plates. The fault is modelled as a discrete dynamical system whose state is described by two variables expressing the slip deficits of the two regions. Because of plate motion, the asperity accumulates stress and eventually releases it, producing an earthquake, when a frictional threshold is exceeded. The weak region is subject to a very slow creep during interseismic intervals and may slip at a higher rate (afterslip) as a consequence of coseismic stress imposed by the asperity failure. The evolution equations of the system are solved analytically for the interseismic intervals, the asperity slip and the afterslip in the weak region. It is found that the amount of afterslip is proportional to the seismic slip of the asperity, in agreement with observations. The model shows that afterslip is a natural consequence of seismic slip in a fault containing a velocity-strengthening region. Afterslip may have any duration, according to the intensity of velocity strengthening, thus accounting for the wide range of observed durations. The model is applied to the fault of the 2011 Tohoku-Oki earthquake. The results suggest that the first four months after the event were dominated by afterslip, while the subsequent postseismic deformation was probably due to viscoelastic relaxation in the asthenosphere.
\end{abstract}

Keywords: Fault model, Asperity, Velocity-strengthening region, Seismic slip, Aseismic slip, Afterslip versus viscoelastic relaxation

\section{Introduction}

It is a common observation that fault slip following an earthquake may continue for some time, at a decreasing rate. This phenomenon is known as afterslip and may last up to several months. It is expected to be the consequence of aseismic slip of a velocity-strengthening region of the fault, which has been loaded by the coseismic slip of a velocity-weakening region (Scholz 1990).

In fact, seismic and geodetic observations have shown that faults can accommodate tectonic motion in different ways. Some fault regions respond with stable, quasi-static motion, with slip rates comparable to tectonic rates; other regions remain locked for decades or centuries and then experience fast slip with emission of seismic waves. Typically, the amount of afterslip is proportional to that

*Correspondence: emanuele.lorenzano2@unibo.it Dipartimento di Fisica e Astronomia, Alma Mater Studiorum Università di Bologna, Viale Carlo Berti Pichat 8, 40127 Bologna, Italy of seismic slip. For instance, afterslip can account for a part of the postseismic deformation following the 1906 San Francisco earthquake (Kenner and Segall 2000).

One way to account for such observations is to separate the fault surface into two kinds of regions: stable regions, which mostly creep, and unstable regions, which produce earthquakes (e.g. Johnson 2010). In studying a thrust earthquake at the Japan Trench, Heki et al. (1997) found that the afterslip distribution was relatively even throughout the fault surface, while the coseismic slip was concentrated in a small central part corresponding to an asperity. Yagi and Kikuchi (2002) acknowledged that afterslip following the 1994 Sanriku-Haruka-Oki earthquake took place in a region adjacent to the asperity whose failure generated the mainshock. However, it has been suggested that in some cases the two regions may not be spatially separated (Noda and Lapusta 2013).

There is obviously an interaction between the two fault regions. The interaction between seismic and aseismic 
fault slip was studied by Dragoni and Tallarico (1992) and Tallarico et al. (2002). Kato $(2004,2014)$ discussed the interplay between velocity-weakening and velocitystrengthening patches on a fault plane and the conditions for seismic and aseismic slip events. Dublanchet et al. (2013) and Yabe and Ide (2017) considered a fault with a large number of asperities and pointed out that asperity concentration remarkably affects the slip behaviour of heterogeneous faults containing both velocity-weakening and velocity-strengthening regions: specifically, the entire fault may slip seismically if the asperity concentration exceeds a critical threshold. Bulk relaxation of the crust and the effect of pore fluid diffusion may also play a role. Belardinelli and Bonafede (1995) modelled afterslip as driven by viscous flow in the asthenosphere. A study of the effects of viscoelastic relaxation on a complex fault was made by Amendola and Dragoni (2013) and Dragoni and Lorenzano (2015).

Several empirical relationships have been proposed in order to describe aseismic slip. Nason and Weertman (1973) proposed an exponential function approaching a constant value. More recently, observations and theoretical considerations suggested that afterslip can be represented as a logarithmic function of time (Marone et al. 1991). Even though this function represents well the observations in many cases, it yields a slip that increases indefinitely with time and must be truncated ad hoc. A discussion of different time functions was presented by Barbot et al. (2009).

Seismic and aseismic slip in a two-degree-of-freedom spring-block model was studied by Yoshida and Kato (2003). Friction on the blocks was described by means of a rate- and state-dependent friction law. Under the condition of velocity-weakening for one block and velocitystrengthening for the other, afterslip was found as a result of the relaxation of the stress imposed on the latter by the sudden slip of the former. The model was further investigated by Abe and Kato (2013) employing a different expression for the friction law and assuming a velocityweakening behaviour for both blocks. Numerical simulations were carried out using different initial conditions for the stiffnesses of the coupling springs, and several slip patterns were acknowledged accordingly, including stable sliding, seismic and aseismic slip. In both papers, the evolution equations were solved numerically.

The aim of the present study is to obtain afterslip as a dynamic mode of a fault containing two regions with different mechanical behaviours: a strong, velocity-weakening region (asperity) and a weak, velocity-strengthening region. The two regions may have different areas and seismic wave radiation associated with asperity slip is considered. We base on a model developed by Dragoni and Santini (2015) and Dragoni and Tallarico (2016), where the average values of stress, friction and slip are considered for each region, so that the fault is described as a discrete dynamical system (Ruff 1992; Rice 1993; Turcotte 1997). Such an approach has the advantage of reducing the number of degrees of freedom required to describe the dynamics of the fault; furthermore, it allows the study of the evolution of the system by means of orbits in the phase space, making it possible to better visualize the different aspects of the dynamics. On the whole, models with a finite number of degrees of freedom allow to focus on the main features of the seismic source, while avoiding the more complicated characterization based on continuum mechanics.

We describe the different stages of fault behaviour, including the interaction between the weak region and the asperity responsible for earthquakes. During the interseismic intervals, the asperity accumulates stress that is released by asperity slip in seismic events. When the asperity slips, it transfers stress to the weak region, triggering the afterslip. In the same way, we expect that afterslip transfers stress back to the asperity, thus changing its state and subsequent evolution. An analytical solution for the evolution equations of the system will be obtained.

As an example, we apply the model to the fault of the 2011 Tohoku-Oki earthquake. The moment rate function associated with this event was dominated by one single hump (Wei et al. 2012), making it appropriate to ascribe the seismic slip to a large unstable region on the fault plane; what is more, this earthquake was followed by a prolonged afterslip episode (Ozawa et al. 2011). Observations show that seismic slip concentrated in a compact area at shallow depth, while afterslip occurred on a similar area downslip (Lay et al. 2012; Silverii et al. 2014). A part of postseismic deformation was certainly due to viscoelastic relaxation in the asthenosphere (Sun et al. 2014; Yamagiwa et al. 2015), and an attempt will be made to discriminate between the two mechanisms.

\section{The model}

We consider a plane fault embedded in a shear zone between two tectonic plates moving at constant relative velocity $v$. The shear zone is assumed to be a homogeneous and isotropic Hooke solid with rigidity $\mu$. As a consequence of plate motion, the fault is subject to a tangential strain rate $\dot{e}$.

The fault contains two regions with different mechanical behaviours: a strong region (asperity) with a high static friction and a velocity-weakening dynamic friction and a weak region with a negligible static friction and a velocity-strengthening dynamic friction. Henceforth, symbols with an index 1 refer to the asperity and symbols with an index 2 refer to the weak region. 
The two regions have areas $A_{1}$ and $A_{2}$, respectively and the distance between their centres is $a$ (Fig. 1). They are allowed to slip in the direction of the tangential traction imposed by the motion of tectonic plates. Their slip is controlled by their constitutive equations and by the forces exerted by the surrounding medium. We introduce a discrete fault model where the average values of stress, friction and slip on each region are considered. The state of the fault is described by two variables: the slip deficits $x(t)$ and $y(t)$ of the asperity and of the weak region, respectively, as functions of time $t$. At a certain instant $t$ in time, the slip deficit of a fault region is defined as the slip that such region should undergo in order to recover the relative plate displacement occurred up to time $t$.

Of course, this is a simplification of fault mechanics. Considering only the average values of stress, friction and slip on a fault region entails that the region moves as a rigid surface and slip propagation within the region is not allowed. However, we are mostly interested in the effect of asperity slip on the weak region. Since asperity slip is very fast with respect to afterslip, the final asperity dislocation is more relevant than the detailed space-time history of slip. In the case of afterslip, the model does not describe the possible propagation of slip on the weak region, but assumes that slip involves the final area since the beginning. Since the two regions move as rigid surfaces, it is simpler to use forces instead of tractions. Let $f_{1}$ and $f_{2}$ be the tangential forces applied to the asperity and to the weak region in the slip direction and let $f_{1}^{\prime}$ and $f_{2}^{\prime}$ be the frictional resistances. The evolution equations for the two regions can be written as

$$
\begin{aligned}
& \mu_{1} \ddot{x}=f_{1}+f_{1}^{\prime} \\
& \mu_{2} \ddot{y}=f_{2}+f_{2}^{\prime}
\end{aligned}
$$

where $\mu_{1}$ and $\mu_{2}$ are the masses associated with the two regions and dots indicate differentiation with respect to $t$. The force $f_{1}$ applied to the asperity includes three terms: the elastic force due to plate motion, the elastic force due

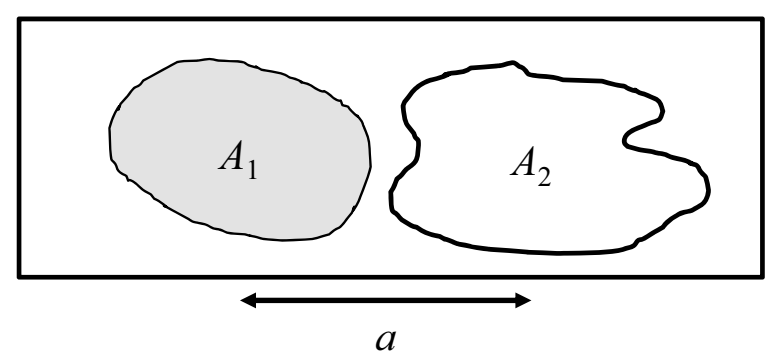

Fig. 1 Sketch of the fault model. An asperity with area $A_{1}$ and a weak region with area $A_{2}$ are shown. The rectangular frame is the fault border. The state of the fault is described by the slip deficits $x(t)$ and $y(t)$ of the two regions to a difference in the slip deficits of the two regions and a rate-dependent force due to radiation damping (e.g. Rice 1993). It can be written as

$$
f_{1}=-K_{1} x-K_{c}(x-y)-\Gamma \dot{x}
$$

where $K_{1}$ and $K_{c}$ are coupling constants and $\Gamma$ is the impedance of the medium. The force $f_{2}$ applied to the weak region includes only the first two terms:

$$
f_{2}=-K_{2} y-K_{c}(y-x)
$$

where $K_{2}$ is a coupling constant. The coupling constants can be expressed as

$$
\begin{aligned}
& K_{1}=\frac{2 \mu \dot{e} A_{1}}{v}, \quad K_{2}=\frac{2 \mu \dot{e} A_{2}}{v} \\
& K_{c}=\mu A_{1} A_{2} s
\end{aligned}
$$

where $s$ is the average tangential traction (per unit moment) that the dislocation of one region imposes to the other one. According to (3) and (4), the forces applied to each region depend on $x$ and $y$, so that a change in $x$ or $y$ entails a change in both forces, hence a change in the stress distribution on the fault. The interaction between the two regions is controlled by the constant $K_{c}$.

The gravity force is neglected. In fact, it has a role only when movements have a vertical component, so it intervenes only in dip-slip faulting. However, the variables $x$ and $y$ express the relative motion of fault walls. The effect of gravity on the motion of one wall is opposite to the effect on the other one. There is not exact compensation, but this suffices to render gravity a second-order effect that can be ignored in a first approximation. Neglecting gravity has the effect to slightly overestimate or underestimate dynamic friction. As to friction, we use simplified versions of the general rate and state-dependent law. For the asperity, we assume a velocity-weakening law, characterized by a static friction $f_{\mathrm{s}}$ and an average dynamic friction $f_{\mathrm{d}}$ :

$$
f_{1}^{\prime}= \begin{cases}f_{\mathrm{s}}, & \dot{x}=0 \\ f_{\mathrm{d}}, & \dot{x} \neq 0\end{cases}
$$

For the weak region, we assume a velocity-strengthening law

$$
f_{2}^{\prime}=f_{0}-\Lambda \dot{y}
$$

where $f_{0}$ is the steady-state dynamic friction and $\Lambda$ is a constant. The minus sign is due to the fact that $\dot{y}<0$ during fault slip. The evolution equations for the two regions are then

$$
\begin{aligned}
& \mu_{1} \ddot{x}+\Gamma \dot{x}+\left(K_{1}+K_{c}\right) x-K_{c} y-f_{\mathrm{d}}=0 \\
& \mu_{2} \ddot{y}+\Lambda \dot{y}+\left(K_{2}+K_{c}\right) y-K_{c} x-f_{0}=0
\end{aligned}
$$


Hence, the evolution of the fault is governed by a system of two coupled ordinary differential equations. We exclude simultaneous slip of the two regions (e.g. Dublanchet et al. 2013; Yabe and Ide 2017), even though it could be easily treated by models describing the dynamics of faults with two asperities (e.g. Dragoni and Santini 2015; Dragoni and Tallarico 2016). Accordingly, the system has three dynamic modes, corresponding to evolution in the interseismic interval, seismic slip of the asperity and afterslip in the weak region. We now specialize Eqs. (9) and (10) for the three modes.

1. During interseismic intervals, $f_{1}<f_{\mathrm{s}}$ by definition, so that the asperity is stationary. However, its slip deficit $x$ increases due to tectonic loading. As to the weak region, we allow a steady-state creep at constant stress, so that its slip deficit $y$ increases with time, but slower than $x$. Equations (9) and (10) become

$\ddot{x}=0$

$\left(K_{2}+K_{c}\right) y-K_{c} x=f_{0}$

2. During asperity slip, both tectonic loading and steady-state creep can be neglected, because they give negligible contributions in such a short time. Equations (9) and (10) become

$$
\begin{aligned}
& \mu_{1} \ddot{x}+\Gamma \dot{x}+\left(K_{1}+K_{c}\right) x-K_{c} y-f_{\mathrm{d}}=0 \\
& \dot{y}=0
\end{aligned}
$$

3. During afterslip in the weak region, the asperity is stationary. Afterslip has a much shorter duration than typical interseismic intervals; therefore, we neglect tectonic loading also in this case. Equations (9) and (10) become

$$
\begin{aligned}
& \dot{x}=0 \\
& \mu_{2} \ddot{y}+\Lambda \dot{y}+\left(K_{2}+K_{c}\right) y-K_{c} x-f_{0}=0
\end{aligned}
$$

\section{Solutions}

In order to solve the evolution equations, we employ a dimensionless formulation. We introduce nondimensional variables and time

$$
X=\frac{K_{1} x}{f_{\mathrm{s}}}, \quad Y=\frac{K_{1} y}{f_{\mathrm{s}}}, \quad T=\sqrt{\frac{K_{1}}{\mu_{1}}} t
$$

and nondimensional forces

$$
F_{1}=\frac{f_{1}}{f_{\mathrm{s}}}, \quad F_{2}=\frac{f_{2}}{f_{\mathrm{s}}}
$$

We also introduce the following nondimensional parameters:

$$
\begin{aligned}
& \alpha=\frac{K_{c}}{K_{1}}, \quad \beta=\frac{f_{0}}{f_{\mathrm{s}}}, \quad \gamma=\frac{\Gamma}{\sqrt{K_{1} \mu_{1}}} \\
& \epsilon=\frac{f_{\mathrm{d}}}{f_{\mathrm{s}}}, \quad \lambda=\frac{\Lambda}{\sqrt{K_{1} \mu_{1}}}, \quad \xi=\frac{A_{2}}{A_{1}}, \quad V=\frac{\sqrt{K_{1} \mu_{1}}}{f_{\mathrm{s}}} v
\end{aligned}
$$

where $\alpha$ expresses the coupling between the asperity and the weak region; $\beta$ is the ratio between the steadystate frictional stress of the weak region and the static frictional stress of the asperity; $\gamma$ is a function of the seismic efficiency of the asperity; $\epsilon$ is the ratio between the dynamic and the static frictions of the asperity; $\lambda$ measures the intensity of velocity strengthening; $\xi$ is the ratio between the areas of the two regions; $V$ is the nondimensional velocity of tectonic plates. The parameter values have the following ranges: $\alpha \geq 0,0<\beta<1, \gamma \geq 0, \lambda>0,0<\epsilon<1, \xi>0, V>0$. We also assume that the masses associated with the two regions are proportional to their areas: accordingly,

$$
\frac{\mu_{2}}{\mu_{1}}=\frac{K_{2}}{K_{1}}=\xi
$$

where (5) was employed. Hence, the forces (3) and (4) become

$$
\begin{aligned}
& F_{1}=-(1+\alpha) X+\alpha Y-\gamma \dot{X} \\
& F_{2}=-(\alpha+\xi) Y+\alpha X
\end{aligned}
$$

We next express the evolution equations for the three dynamic modes in nondimensional form and give their solutions.

\section{Interseismic intervals}

The evolution Eqs. (11) and (12) become

$$
\begin{aligned}
& \ddot{X}=0 \\
& (\alpha+\xi) Y-\alpha X=\beta
\end{aligned}
$$

where dots indicate differentiation with respect to $T$. With initial conditions

$$
X(0)=X_{0}, \quad \dot{X}(0)=V, \quad Y(0)=Y_{0}
$$

their solution is

$$
\begin{aligned}
& X(T)=X_{0}+V T \\
& Y(T)=Y_{0}+\frac{\alpha}{\alpha+\xi} V T
\end{aligned}
$$

where, according to (25),

$$
Y_{0}=\frac{\alpha X_{0}+\beta}{\alpha+\xi}
$$


The solution shows that the slip deficit $X$ of the asperity increases in time with the velocity $V$ of tectonic plates, so that the asperity is stationary. The slip deficit $Y$ of the weak region also increases in time, but with a lower rate

$$
\dot{Y}=\frac{\alpha}{\alpha+\xi} V
$$

implying a steady creep $\Delta Y(T)$ with constant rate

$$
\Delta \dot{Y}=V-\dot{Y}=\frac{\xi}{\alpha+\xi} V
$$

that is smaller than plate velocity. From (22) and (23), the forces on the two regions are

$$
\begin{aligned}
& F_{1}(T)=-(1+\alpha) X(T)+\alpha Y(T) \\
& F_{2}(T)=-(\alpha+\xi) Y(T)+\alpha X(T)
\end{aligned}
$$

Thanks to (27) and (28), they become

$$
\begin{aligned}
& F_{1}(T)=F_{1}(0)-\frac{\alpha+\alpha \xi+\xi}{\alpha+\xi} V T \\
& F_{2}=-\beta
\end{aligned}
$$

where

$$
F_{1}(0)=-(1+\alpha) X_{0}+\alpha Y_{0}
$$

showing that stress increases linearly with time on the asperity, while it remains constant on the weak region.

\section{Seismic slip}

We suppose that asperity slip starts at $T=T_{1}$, when the forces have the values

$$
F_{1}=-1, \quad F_{2}=-\beta
$$

Thanks to (32) and (33), they can be written as

$$
\begin{aligned}
& (1+\alpha) X-\alpha Y=1 \\
& (\alpha+\xi) Y-\alpha X=\beta
\end{aligned}
$$

The system of the two equations yields the state of the fault at the beginning of the seismic event:

$$
X_{1}=\frac{\alpha+\alpha \beta+\xi}{\alpha+\alpha \xi+\xi}, \quad Y_{1}=\frac{\alpha+\alpha \beta+\beta}{\alpha+\alpha \xi+\xi}
$$

The evolution Eqs. (13) and (14) become

$$
\begin{aligned}
& \ddot{X}+\gamma \dot{X}+(1+\alpha) X-\alpha Y_{1}-\epsilon=0 \\
& \dot{Y}=0
\end{aligned}
$$

We solve (41) in the case of weak damping, implying that the rate-dependent term is small with respect to the other forces: this choice is suggested by the fact that the seismic efficiency of faults is small (e.g. Kanamori 2001). If we set $T_{1}=0$ for the sake of simplicity, the initial conditions are

$$
X(0)=X_{1}, \quad \dot{X}(0)=0, \quad Y(0)=Y_{1}
$$

and the solution is

$$
X(T)=X_{1}-\frac{U}{2}\left[1-\left(\cos \omega_{1} T+\frac{\gamma}{2 \omega_{1}} \sin \omega_{1} T\right) \mathrm{e}^{-\frac{\gamma}{2} T}\right]
$$

$$
Y=Y_{1}
$$

where

$$
U=2 \frac{1-\epsilon}{1+\alpha}
$$

and

$$
\omega_{1}=\sqrt{1+\alpha-\frac{\gamma^{2}}{4}}
$$

The duration of the seismic event, calculated by setting $\dot{X}=0$, is

$$
T_{\mathrm{s}}=\frac{\pi}{\omega_{1}}
$$

The slip amplitude of the asperity is defined as

$$
\Delta X(T)=X_{1}-X(T)
$$

and the final amplitude is

$$
U_{\mathrm{s}}=\kappa U
$$

where

$$
\kappa=\frac{1}{2}\left(1+\mathrm{e}^{-\frac{\gamma}{2} T_{\mathrm{s}}}\right)
$$

The moment rate of the seismic event can be calculated as

$$
\dot{M}_{\mathrm{s}}(T)=M_{1} \frac{\Delta \dot{X}(T)}{U}
$$

where $M_{1}$ is a reference seismic moment, corresponding to slip $U$. From (49) and (44), we obtain

$$
\dot{M}_{\mathrm{s}}(T)=M_{1} \frac{1+\alpha}{2 \omega_{1}} \sin \omega_{1} T \mathrm{e}^{-\frac{\gamma}{2} T}
$$

The final seismic moment is

$$
M_{\mathrm{s}}=\kappa M_{1}
$$

From (22) and (23), the forces on the asperity and on the weak region during the event are

$$
\begin{aligned}
& F_{1}(T)=-(1+\alpha) X(T)+\alpha Y_{1}-\gamma \dot{X}(T) \\
& F_{2}(T)=-(\alpha+\xi) Y_{1}+\alpha X(T)
\end{aligned}
$$


At the end of the event $\left(T=T_{2}\right)$, the slip deficits of the two regions are

$$
X_{2}=X_{1}-\kappa U, \quad Y_{2}=Y_{1}
$$

Introducing (57) into (55) and (56), we obtain the forces

$$
\begin{aligned}
& F_{1}\left(T_{2}\right)=-1+(1+\alpha) U_{\mathrm{s}} \\
& F_{2}\left(T_{2}\right)=-\beta-\alpha U_{\mathrm{s}}
\end{aligned}
$$

The force $F_{1}$ on the asperity has decreased in magnitude, with a force drop

$$
\Delta F_{1}=(1+\alpha) U_{\mathrm{s}}
$$

At the same time, the force $F_{2}$ on the weak region has increased in magnitude by an amount $\alpha U_{\mathrm{s}}$ : this drives the region out of the steady-state creep and starts the afterslip.

\section{Afterslip}

In dimensionless form, the evolution Eqs. (15) and (16) become

$$
\begin{aligned}
& \dot{X}=0 \\
& \xi \ddot{Y}+\lambda \dot{Y}+(\alpha+\xi) Y-\alpha X_{2}-\beta=0
\end{aligned}
$$

Since afterslip has a long duration with respect to seismic slip, a high value of $\lambda$ is expected; hence, we consider the overdamped solution of (62). If we set $T_{2}=0$ for the sake of simplicity, initial conditions are

$$
X(0)=X_{2}, \quad Y(0)=Y_{2}, \quad \dot{Y}(0)=0
$$

and the solution is

$$
X=X_{2}
$$

$$
Y(T)=\bar{Y}-\left(\bar{Y}-Y_{1}\right)\left(\cosh \omega_{2} T+\frac{\lambda}{2 \xi \omega_{2}} \sinh \omega_{2} T\right) \mathrm{e}^{-\frac{\lambda}{2 \xi} T}
$$

where

$$
\bar{Y}=\frac{\alpha X_{2}+\beta}{\alpha+\xi}
$$

and

$$
\omega_{2}=\sqrt{\frac{\lambda^{2}}{4 \xi^{2}}-1-\frac{\alpha}{\xi}}
$$

The afterslip amplitude is

$$
\Delta Y(T)=Y_{1}-Y(T)
$$

or

$$
\Delta Y(T)=U_{\mathrm{a}}\left[1-\left(\cosh \omega_{2} T+\frac{\lambda}{2 \xi \omega_{2}} \sinh \omega_{2} T\right) \mathrm{e}^{-\frac{\lambda}{2 \xi} T}\right]
$$

with a final value

$$
U_{\mathrm{a}}=Y_{1}-\bar{Y}
$$

Thanks to (40), (50), (57) and (66), we obtain

$$
U_{\mathrm{a}}=\frac{\alpha}{\alpha+\xi} U_{\mathrm{s}}
$$

showing that afterslip in the weak region is proportional to the seismic slip of the asperity, in agreement with observations (e.g. Scholz 1990). The state of the fault at the end of afterslip is then

$$
X_{3}=X_{2}, \quad Y_{3}=\bar{Y}
$$

It is noteworthy that $X_{3}$ and $Y_{3}$ satisfy (24) and (25), i.e. the evolution equations for interseismic intervals. Hence, the system can go through a cycle made of a sequence of its three dynamic modes.

From (69) and (71), the afterslip rate is

$$
\Delta \dot{Y}(T)=\frac{\alpha U_{\mathrm{s}}}{\xi \omega_{2}} \sinh \omega_{2} T \mathrm{e}^{-\frac{\lambda}{2 \xi} T}
$$

The geodetic moment rate associated with afterslip is

$$
\dot{M}_{\mathrm{a}}(T)=\xi M_{1} \frac{\Delta \dot{Y}(T)}{U}
$$

whence

$$
\dot{M}_{\mathrm{a}}(T)=M_{1} \frac{\alpha \kappa}{\omega_{2}} \sinh \omega_{2} T \mathrm{e}^{-\frac{\lambda}{2 \xi} T}
$$

and the final moment is

$$
M_{\mathrm{a}}=\frac{\alpha \xi}{\alpha+\xi} \kappa M_{1}
$$

differing from the seismic moment (54) by a factor $\alpha \xi /(\alpha+\xi)$. According to (69), the final value $U_{\mathrm{a}}$ of afterslip is reached only for $T \rightarrow \infty$. However, the slip rate $\Delta \dot{Y}$ is exponentially decreasing and, after some time, afterslip becomes indistinguishable from the steady-state creep typical of interseismic intervals. Therefore, we can assign afterslip a finite duration, defined as the time interval $T_{\mathrm{a}}$ after which the afterslip rate (73) lowers below the creep rate (31):

$$
\Delta \dot{Y}\left(T_{\mathrm{a}}\right)=\frac{\xi}{\alpha+\xi} V
$$

The equation can be easily solved for $T_{\mathrm{a}}$ if we note that, for large values of $T$, we can write to a very good approximation

$$
\Delta \dot{Y}(T)=\frac{\alpha U_{\mathrm{s}}}{2 \xi \omega_{2}} \mathrm{e}^{-T / \Theta}
$$

where

$$
\Theta=\left(\frac{\lambda}{2 \xi}-\omega_{2}\right)^{-1}
$$


Then (77) yields

$$
T_{\mathrm{a}}=\Theta \ln \frac{\alpha U_{\mathrm{s}}(\alpha+\xi)}{2 \xi^{2} \omega_{2} V}
$$

Afterslip duration $T_{\mathrm{a}}$ is remarkably affected by the degree of coupling between the two regions of the fault. This is illustrated in Fig. 2, where $T_{\mathrm{a}}$ is shown as a function of the coupling parameter $\alpha$ for different values of the parameter $\xi$. The graph shows an initial steep growth for smaller values of $\alpha$, reaching a maximum value that depends on the particular combination of the parameters of the system; finally, it decreases for higher values of $\alpha$. From (22) and (23), the forces acting on the asperity and on the weak region during afterslip are, respectively,

$$
\begin{aligned}
& F_{1}(T)=-(1+\alpha) X_{2}+\alpha Y(T) \\
& F_{2}(T)=-(\alpha+\xi) Y(T)+\alpha X_{2}
\end{aligned}
$$

If we introduce expressions (72) for $X_{3}$ and $Y_{3}$, we obtain the forces at the end of afterslip $\left(T=T_{3}\right)$

$$
\begin{aligned}
& F_{1}\left(T_{3}\right)=-1+\frac{\alpha+\alpha \xi+\xi}{\alpha+\xi} U_{\mathrm{s}} \\
& F_{2}\left(T_{3}\right)=-\beta
\end{aligned}
$$

The force $F_{1}$ on the asperity has increased (in magnitude) with respect to its value at $T=T_{2}$, because afterslip transfers stress to the asperity. A comparison with (58) shows that $F_{1}$ has increased by an amount $\alpha U_{\mathrm{a}}$; hence, it is closer to the condition for asperity failure. The amount of stress transferred to the asperity significantly increases with the coupling parameter $\alpha$; however, $F_{1}\left(T_{3}\right)>-1$,

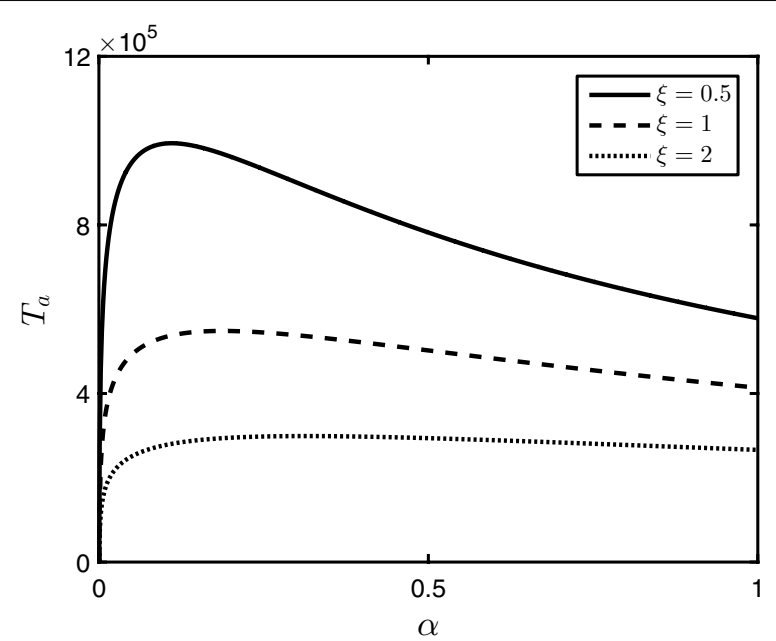

Fig. 2 Afterslip duration. The afterslip duration (80) is plotted as a function of the coupling parameter $\alpha$ for different values of the parameter $\xi$. Other parameters are $\epsilon=0.7, \gamma=1, \lambda=10^{5}$ and $V=10^{-9}$ which guarantees that afterslip never triggers asperity failure. Nevertheless, the amount of stress that afterslip transfers to the asperity will produce a time advance of the next earthquake. This is illustrated in Fig. 3, where $F_{1}\left(T_{3}\right)$ is shown as a function of $\alpha$ for different values of the parameter $\xi$. The force $F_{2}$ on the weak region shows that the condition for steady-state creep has been recovered.

\section{Subsequent evolution}

We can now calculate the duration $T_{i s}$ of the next interseismic interval. We see from (83) that, in order to reach the unit value, $F_{1}$ must increase in magnitude by an amount

$$
\Delta F_{1}=\frac{\alpha+\alpha \xi+\xi}{\alpha+\xi} U_{\mathrm{s}}
$$

This requires a time

$$
T_{i \mathrm{~s}}=\frac{\Delta F_{1}}{\left|\dot{F}_{1}\right|}
$$

where $\dot{F}_{1}$ is the rate of increase of $F_{1}$ that can be calculated from (34). We obtain

$$
T_{i \mathrm{~s}}=\frac{U_{\mathrm{s}}}{V}
$$

In order to enlighten the role of afterslip, we calculate the interseismic interval $T_{i \mathrm{~s}}^{\prime}$ in the absence of afterslip. In this case, according to (58), $F_{1}$ must increase in magnitude by an amount

$$
\Delta F_{1}^{\prime}=(1+\alpha) U_{\mathrm{s}}
$$

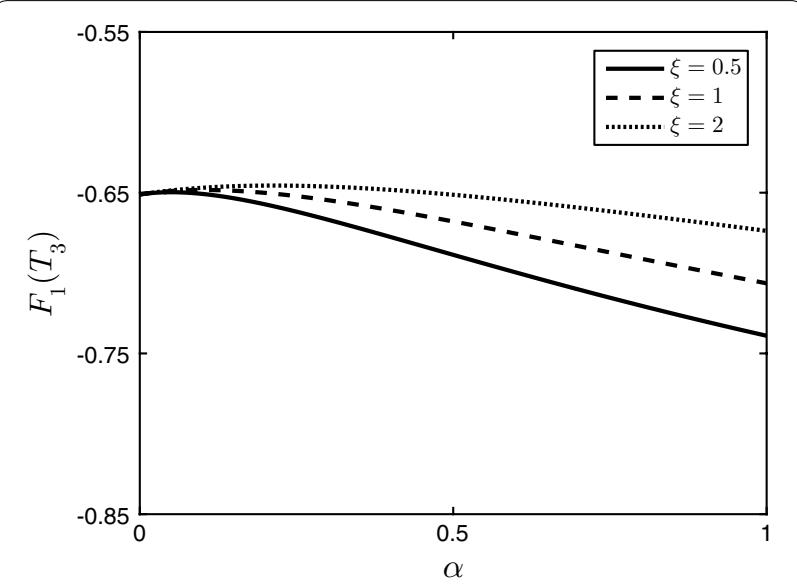

Fig. 3 Tangential force on the asperity at the end of afterslip. The tangential force (83) is plotted as a function of the coupling parameter $\alpha$ for different values of the parameter $\xi$. Other parameters are $\epsilon=0.7$ and $\gamma=1$ 
so that

$$
T_{i \mathrm{~s}}^{\prime}=\frac{(1+\alpha)(\alpha+\xi)}{\alpha+\alpha \xi+\xi} \frac{U_{\mathrm{s}}}{V}
$$

The ratio between the two times is

$$
\frac{T_{i \mathrm{~s}}}{T_{i \mathrm{~s}}^{\prime}}=1-\frac{\alpha^{2}}{(1+\alpha)(\alpha+\xi)}
$$

Since $\alpha$ and $\xi$ are positive, the ratio is always smaller than 1 , meaning that the following earthquake is anticipated by the occurrence of afterslip.

From (31) and (87), the cumulative creep in the interseismic interval is

$$
U_{i \mathrm{~s}}=\frac{\xi}{\alpha+\xi} U_{\mathrm{s}}
$$

corresponding to a geodetic moment

$$
M_{i \mathrm{~s}}=\frac{\xi^{2}}{\alpha+\xi} M_{\mathrm{s}}
$$

Comparing (92) with (54) and (76), we see that, in a cycle including the three dynamic modes, the total geodetic moment is a fraction $\xi$ of the seismic moment and the total moment release is

$$
M=(1+\xi) M_{\mathrm{s}} .
$$

\section{Discussion}

In order to test the model, it is necessary to assign appropriate values to the parameters. They will be chosen within the allowed ranges, but do not pertain to any real case. A different set of parameters would imply different values of the quantities characterizing the seismic cycle, but would not alter the general conclusions of this section.

As an example, we consider a fault zone with rigidity $\mu=30 \mathrm{GPa}$, in the presence of a relative plate velocity $v=3 \mathrm{~cm} \mathrm{a}^{-1}$ and a tangential strain rate $\dot{e}=10^{-14} \mathrm{~s}^{-1}$. We consider a medium-size earthquake produced by a fault with $A_{1}=A_{2}=500 \mathrm{~km}^{2}, a=25 \mathrm{~km}$ and a strikeslip mechanism. We assume that the seismic event has a duration $t_{\mathrm{s}}=10 \mathrm{~s}$ and a slip amplitude $u_{\mathrm{s}}=1 \mathrm{~m}$. The seismic moment is then $m_{\mathrm{s}}=1.5 \times 10^{19} \mathrm{~N} \mathrm{~m}$.

The parameter $\alpha$ can be evaluated from the values of the quantities $A_{2}, v, \dot{e}, a$ and the kind of source mechanism. In fact, from (5) and (6), we have

$$
\alpha=\frac{A_{2} v s}{2 \dot{e}}
$$

For nonoverlapping regions, it is a good approximation to use tractions produced by pointlike dislocations (e.g. Dragoni and Lorenzano 2016)

$$
s=k a^{-3}
$$

where $k=5 /(12 \pi)$ for strike slip and $k=1 /(6 \pi)$ for $\operatorname{dip}$ slip.

It is evident that the value of the distance $a$ may have a strong influence on $\alpha$. In fact, if we increase $a, \alpha$ becomes smaller and smaller. But we cannot decrease $a$ below a certain value without decreasing the area $A_{2}$; otherwise, the two regions would overlap. It follows that $\alpha$ is always much smaller than 1 (in the present example, $\alpha=0.2$ ). From the solutions of the governing equations, it can be seen that $\alpha$ is always summed to unity or to the parameter $\xi$, which is in the order of unity. Therefore, the results are moderately sensible to the value of $\alpha$ and the sensitivity decreases with decreasing $\alpha$. The parameter $\beta$ is by definition smaller than 1 . Since asperity models assume that weak regions may slip at a much lower stress level than asperities, a value $\beta=0.1$ is reasonable, meaning that the force on the weak region is one-tenth of the force on the asperity at the onset of seismic slip. In applications to real cases, the value can be chosen in order that the model gives the best fit with observations. The parameter $\epsilon$ is by definition smaller than 1. Experiments on rock samples suggest values ranging between 0.5 and 1 (Jaeger and Cook 1976). We take $\epsilon=0.7$. Small variations do not have important consequences.

The parameter $\gamma$ is a function of $\alpha, \epsilon$ and the seismic efficiency $\eta$ (Dragoni and Santini 2015). A straightforward calculation yields

$$
\gamma=\frac{2 \sqrt{1+\alpha} \ln \psi}{\sqrt{\pi^{2}+\ln ^{2} \psi}}
$$

where

$$
\psi=\frac{(1-\epsilon)(1-\eta)}{1-\epsilon-\eta(1+\epsilon)}
$$

The seismic efficiency of faults is relatively small, ranging in many cases from 0.1 to 0.3 (e.g. Kanamori 2001). The value 0.15 is in this range and corresponds to $\gamma=1$. According to the previous choice, we consider the value $\xi=1$ for the ratio between the areas of the two regions.

The parameter $V$ can be calculated from the observed plate velocity $v$, the duration $t_{\mathrm{s}}$ and the slip amplitude $u_{\mathrm{s}}$ of the seismic event. From the definitions, we obtain

$$
V=\frac{U_{\mathrm{s}}}{u_{\mathrm{s}}} \frac{t_{\mathrm{s}}}{T_{\mathrm{s}}} v
$$

With the values assumed above, $V=10^{-9}$.

With these values of the model parameters, Fig. 4 shows the main features of the seismic event. The slip amplitude $\Delta X$, the moment rate $\dot{M}_{\mathrm{s}}$ and the forces $F_{1}$ and $F_{2}$ are shown as functions of time in the interval $0 \leq T \leq T_{\mathrm{s}}$. The event duration is $T_{\mathrm{s}} \simeq 3.2$, with a final slip amplitude $U_{\mathrm{s}}=0.30$ and a seismic moment $M_{\mathrm{s}} / M_{1}=0.60$. In 

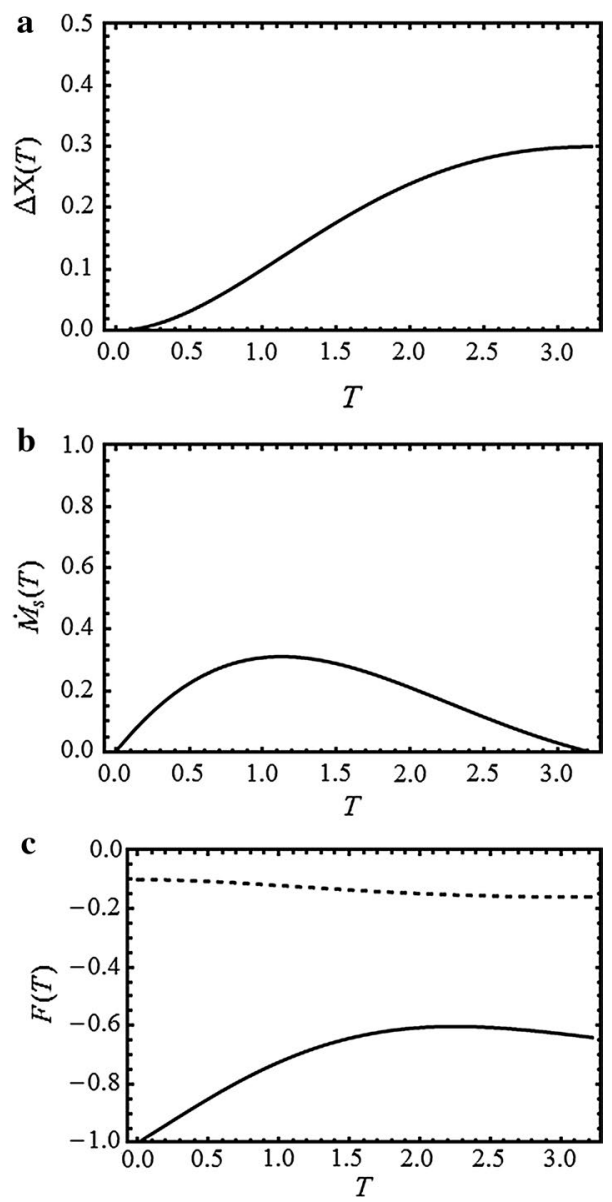

Fig. 4 Seismic slip. The graphs show $\mathbf{a}$ the slip amplitude $\Delta X ; \mathbf{b}$ the associated moment rate $M_{s} ; \mathbf{c}$ the forces $F_{1}$ (solid) and $F_{2}$ (dashed) on the asperity and on the weak region, respectively, as functions of nondimensional time $T$

Fig. 4c, we note a decrease (in magnitude) of the force $F_{1}$ on the asperity and a corresponding increase of the force $F_{2}$ on the weak zone. At the end of the event, the force drop on the asperity is $(1+\alpha) U_{\mathrm{s}}=0.36$, while $F_{2}$ has received a contribution $-\alpha U_{\mathrm{s}}=-0.06$ from the asperity, reaching the value -0.16 .

Calculation of afterslip requires the parameter $\lambda$. Its value controls the afterslip duration $T_{\mathrm{a}}$ and may have large variations. We take $\lambda=10^{5}$, implying an afterslip duration $t_{\mathrm{a}} \simeq 20$ days, if the duration of seismic slip is $t_{\mathrm{s}}=10 \mathrm{~s}$ and $\xi=1$. Since $\lambda$ is much greater than $1-\alpha / \xi$, formula (69) for $\Delta Y$ can be written in a simpler form. Expressing the hyperbolic functions by exponentials, one easily finds

$$
\Delta Y(T)=U_{\mathrm{a}}\left(1-\mathrm{e}^{-T / \Theta}\right)
$$

to a very good approximation.
Figure 5 shows the main features of afterslip. The slip amplitude $\Delta Y$, the moment rate $\dot{M}_{\mathrm{a}}$ and the forces $F_{1}$ and $F_{2}$ are plotted as functions of time in the interval $0 \leq T \leq T_{\mathrm{a}}$. The final slip amplitude is $U_{\mathrm{a}}=0.05$ and the geodetic moment is $M_{\mathrm{a}} / M_{1}=0.10$. According to (71), the total afterslip is about $17 \%$ of seismic slip and the same is for the moment release. At the beginning of afterslip, the force $F_{2}$ is equal to -0.16 . Then, it decreases in magnitude, approaching the value $-\beta$ at the end of afterslip. At the same time, $F_{1}$ increases in magnitude by an amount $\alpha U_{\mathrm{a}}=0.01$.

The sequence of three dynamic modes (seismic slip, afterslip, interseismic evolution) makes a cycle that can be represented in the plane $X Y$ (Fig. 6). The coordinates of points $P_{1}, P_{2}, P_{3}$ are given in (40), (57) and (72), respectively. During the interseismic interval, the representative point of the system moves on line (39). When it reaches $P_{1}$, the seismic event takes place. The point moves by a
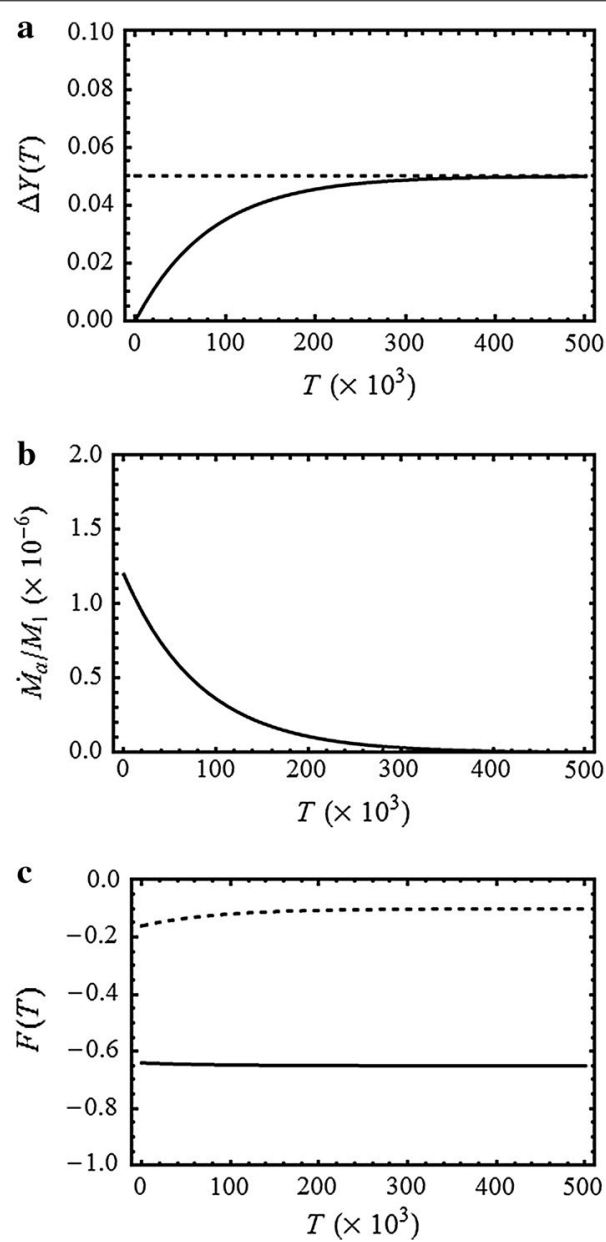

Fig. 5 Afterslip. The graphs show $\mathbf{a}$ the afterslip amplitude $\Delta Y ; \mathbf{b}$ the associated moment rate $M_{a} ; \mathbf{c}$ the forces $F_{1}$ (solid) and $F_{2}$ (dashed) on the asperity and on the weak region, respectively, as functions of nondimensional time $T$ 


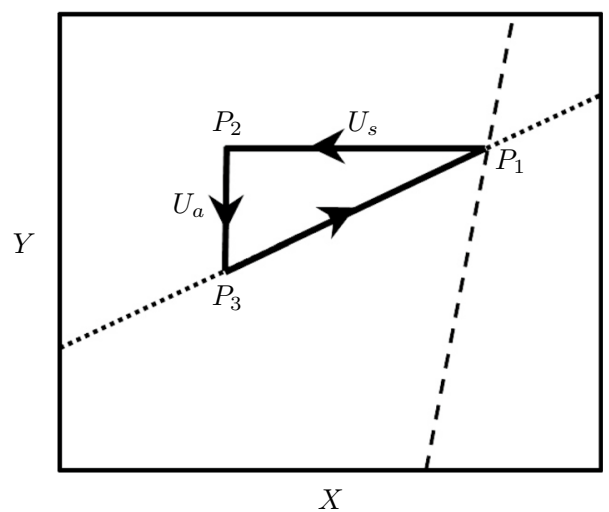

Fig. 6 Geometrical illustration of the cycle made of seismic slip, afterslip and interseismic creep. The dashed line is given by (38), representing the condition for asperity failure. The dotted line is given by (39), representing the condition for interseismic fault creep. The state of the fault is $P_{1}$ at the beginning of the seismic event, $P_{2}$ at the end of the event and $P_{3}$ at the end of afterslip. The lengths of the catheti are the amplitudes $U_{s}$ of seismic slip and $U_{a}$ of afterslip, respectively. From $P_{3}$ to $P_{1}$, the fault is subject to tectonic loading and creep. Arrows indicate the motion of the representative point of the system during the cycle

quantity $U_{\mathrm{s}}$ given by (50), reducing the value of $X$ and reaching $P_{2}$. Here, afterslip begins and lowers the value of

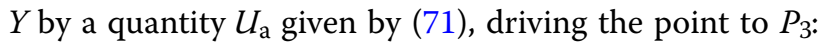
this is again on line (39) and a new interseismic interval begins. The orbit is independent of $\lambda$.

Of course, this cycle represents an ideal situation. There are several factors that may change this scheme. Often the seismic source is not made of a single asperity, but of two or more asperities that introduce complexity in the dynamics (Dragoni and Tallarico 2016). Secondly, the fault is not an isolated system, but is subject to stress perturbations from the slipping of neighbouring faults (Dragoni and Piombo 2015). These complexities may be introduced without difficulty in the model and would break the periodicity of the cycle.

In addition, bulk viscoelastic relaxation of the asthenosphere may add to afterslip as a source of postseismic deformation. The surface displacement associated with postseismic deformation has been often modelled as a function

$$
s(t)=b \ln \left(1+\frac{t}{\tau}\right)
$$

where $b$ is a constant and $\tau$ is a characteristic time (Scholz 1990; Marone et al. 1991; Heki et al. 1997; Barbot et al. 2009). This function becomes arbitrarily large for $t \rightarrow \infty$, even though its derivative tends to zero. In many cases, it fits reasonably well the postseismic deformation data in finite time intervals. On the contrary, (99) yields an afterslip approaching a maximum value $U_{\mathrm{a}}$ and the surface displacement would be

$$
s_{\mathrm{a}}(t)=\bar{s}_{\mathrm{a}}\left(1-\mathrm{e}^{-t / \theta}\right)
$$

where $\bar{s}_{\mathrm{a}}$ is the asymptotic value and

$$
\theta=\frac{t_{\mathrm{a}}}{T_{\mathrm{a}}} \Theta
$$

If we suppose that the asthenosphere is a Maxwell body with a characteristic time $\theta^{\prime}$, the surface displacement produced by viscoelastic relaxation can be written as

$$
s_{v}(t)=\bar{s}_{v}\left(1-\mathrm{e}^{-t / \theta^{\prime}}\right)
$$

where $\bar{s}_{v}$ is the asymptotic value. Due to the high value of the asthenosphere viscosity, the timescale of viscoelastic relaxation is typically much longer than that of afterslip, i.e. $\theta^{\prime} \gg \theta$. Then, if we consider the time interval $0 \leq t \leq t_{\mathrm{a}}$, during which afterslip is observed, we have $t \ll \theta^{\prime}$ and the total displacement is given by

$$
s(t)=s_{\mathrm{a}}\left(1-\mathrm{e}^{-t / \theta}\right)+c t
$$

with $c=\bar{s}_{v} / \theta^{\prime}$. This function has a slope that decreases much slower than $s_{\mathrm{a}}(t)$, thus resembling the logarithmic function (100).

\section{An application: the 2011 Tohoku-Oki earthquake}

The 2011 Tohoku-Oki earthquake was a very large event, with $M_{w}=9.0$ (Ide et al. 2011; Simons et al. 2011; Maercklin et al. 2012). The coseismic slip distribution extended approximately $400 \mathrm{~km}$ along the Japan trench, with a maximum slip ranging between $27 \mathrm{~m}$ (Ozawa et al. 2011) and $80 \mathrm{~m}$ (Iinuma et al. 2012). The data reveal a compact area of large slip, extending from the trench to about $50 \mathrm{~km}$ of depth (Bletery et al. 2014). Afterslip was mostly distributed in an area located downdip of the coseismic slip and extending to a depth of about $100 \mathrm{~km}$ (Lay et al. 2012; Silverii et al. 2014). A major role of viscoelastic relaxation was also suggested (Sun et al. 2014; Yamagiwa et al. 2015).

The relevant data are given in Table 1 . We take an average rigidity of the lithosphere $\mu=40 \mathrm{GPa}$ (Ozawa et al. 2011), a velocity of subduction $v=8 \mathrm{~cm} \mathrm{a}^{-1}$ (Simons et al. 2011) and a surface strain rate $\dot{e}_{\mathrm{s}}=10^{-14} \mathrm{~s}^{-1}$ (Kato et al. 1998). We assume that the fault is made of a velocityweakening and a velocity-strengthening region (Fig. 7). The two regions are rectangles with sides 400 and $150 \mathrm{~km}$ long, so that their areas are $A_{1}=A_{2}=60,000 \mathrm{~km}^{2}$, with a distance $a=150 \mathrm{~km}$ between their centres. We assume an average dip angle $\delta=20^{\circ}$ (Lay et al. 2012). The strain rate on the fault is then (Dragoni and Lorenzano 2016)

$$
\dot{e}=\frac{\sin 2 \delta}{2(1-v)} \dot{e}_{\mathrm{s}}
$$


Table 1 Data for the 2011 Tohoku-Oki earthquake

\begin{tabular}{lll}
\hline$\mu$ & $40 \mathrm{GPa}$ & Rigidity of the lithosphere \\
$v$ & $8 \mathrm{~cm} \mathrm{a}^{-1}$ & Relative plate velocity \\
$\dot{e}$ & $4 \times 10^{-15} \mathrm{~s}^{-1}$ & Tangential strain rate on the fault \\
$\delta$ & $20^{\circ}$ & Average dip angle of the fault \\
$A_{1}$ & $6 \times 10^{4} \mathrm{~km}^{2}$ & Area of the asperity \\
$A_{2}$ & $6 \times 10^{4} \mathrm{~km}^{2}$ & Area of the weak region \\
$a$ & $150 \mathrm{~km}$ & Distance between the centres of the two regions \\
$m_{\mathrm{s}}$ & $3.5 \times 10^{22} \mathrm{~N} \mathrm{~m}$ & Seismic moment of the event \\
$u_{\mathrm{s}}$ & $15 \mathrm{~m}$ & Average slip of the asperity \\
$t_{\mathrm{s}}$ & $80 \mathrm{~s}$ & Duration of seismic slip \\
$t_{\mathrm{a}}$ & 15 days & Assumed duration of afterslip \\
\hline
\end{tabular}

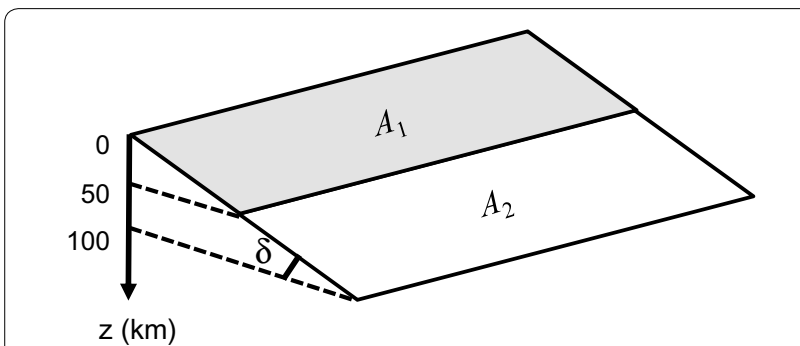

Fig. 7 Fault model of the 2011 Tohoku-Oki earthquake. $A_{1}$ and $A_{2}$ are the areas of the asperity and of the weak region, respectively, and $z$ is depth. The model is a simplified version of the tectonic settings suggested by Lay et al. (2012) and Silverii et al. (2014)

where $v$ is the Poisson modulus, which we take equal to 0.25 . Accordingly, we get $\dot{e} \simeq 4 \times 10^{-15} \mathrm{~s}^{-1}$.

The duration of the seismic event was about $160 \mathrm{~s}$, with a moment rate concentrated in a time interval $t_{\mathrm{s}}=80 \mathrm{~s}$ and a seismic moment $m_{\mathrm{s}}=3.5 \times 10^{22} \mathrm{~N} \mathrm{~m}$ (Maercklin et al. 2012; Wei et al. 2012; Bletery et al. 2014). Accordingly, the average seismic slip was $u_{\mathrm{s}}=15 \mathrm{~m}$.

From these data, we evaluate the values of the model parameters $\alpha, \xi$ and $V$. The value of $\epsilon$ is taken as in the previous section. The value of $\gamma$, corresponding to a seismic efficiency $\eta=0.17$, is chosen in order to obtain the best fit for the moment rate. The value of $\lambda$ will be evaluated on the basis of the assumed afterslip duration. The values are given in Table 2. Notice that we aim to investigate only the seismic slip and afterslip phases associated with the event, whose evolutions are independent of $\beta$ (as shown in "Seismic slip" and "Afterslip" sections); therefore, we do not need to assign a value to this parameter.

We reproduce the observed seismic moment rate in a time interval $t_{1} \leq t \leq t_{2}$, where the dominant contribution to seismic moment is produced. In dimensional form, the moment rate (53) becomes

$$
\dot{m}_{\mathrm{s}}(t)=m_{1} \frac{1+\alpha}{2 \omega_{1}} \chi \sin \omega_{1} \chi\left(t-t_{1}\right) \mathrm{e}^{-\frac{\gamma}{2} \chi\left(t-t_{1}\right)}
$$

Table 2 Values of model parameters for the 2011 TohokuOki fault

\begin{tabular}{lll}
\hline$\alpha$ & 0.3 & Coupling parameter between the two fault regions \\
$\gamma$ & 1.5 & A measure of seismic efficiency \\
$\epsilon$ & 0.7 & Ratio between dynamic and static frictions on the asperity \\
$\lambda$ & $10^{5}$ & A measure of intensity of velocity strengthening \\
$\xi$ & 1 & Ratio between the areas of the two regions \\
$V$ & $10^{-9}$ & Nondimensional plate velocity \\
\hline
\end{tabular}

where

$$
\chi=\frac{T_{\mathrm{s}}}{t_{2}-t_{1}}
$$

and

$$
m_{1}=\mu A_{1} u
$$

where $u$ is the slip that would be observed in the case $\gamma=0$. Hence,

$$
u=\frac{u_{\mathrm{s}}}{\kappa}
$$

The final seismic moment is

$$
m_{\mathrm{s}}=\kappa m_{1}
$$

The moment rate $\dot{m}_{\mathrm{s}}(t)$, calculated from (106) with $t_{1}=50 \mathrm{~s}$ and $t_{2}=130 \mathrm{~s}$, is shown in Fig. 8a. It is superimposed to the observed moment rate given by Wei et al. (2012) and fits well the central peak. The seismic moment calculated from (110) is $m_{\mathrm{s}}=3.6 \times 10^{22} \mathrm{~N} \mathrm{~m}$, in agreement with observation. Figure $8 \mathrm{~b}$ shows the evolution of forces on the asperity and on the weak region during the earthquake, calculated from (55) and (56). The magnitude of $F_{1}$ has a decrease of $32 \%$, while that of $F_{2}$ has an increase of $26 \%$ with respect to the initial value. The stress drop on the asperity can be calculated as

$$
\Delta \sigma=\frac{f_{\mathrm{s}}}{A_{1}} \Delta F_{1}
$$

where $\Delta F_{1}$ is given by $(60)$ and $f_{\mathrm{s}}$ can be estimated as

$$
f_{\mathrm{s}}=\frac{K_{1} u}{U}
$$

where we used (17). Accordingly, we have

$$
\Delta \sigma=\frac{(1+\alpha) K_{1} u_{\mathrm{s}}}{A_{1}}
$$

It results $\Delta \sigma \simeq 3 \mathrm{MPa}$, which has the same order of magnitude as the values given by Bletery et al. (2014).

With regard to postseismic deformation, (71) predicts that the average afterslip amplitude on the weak 

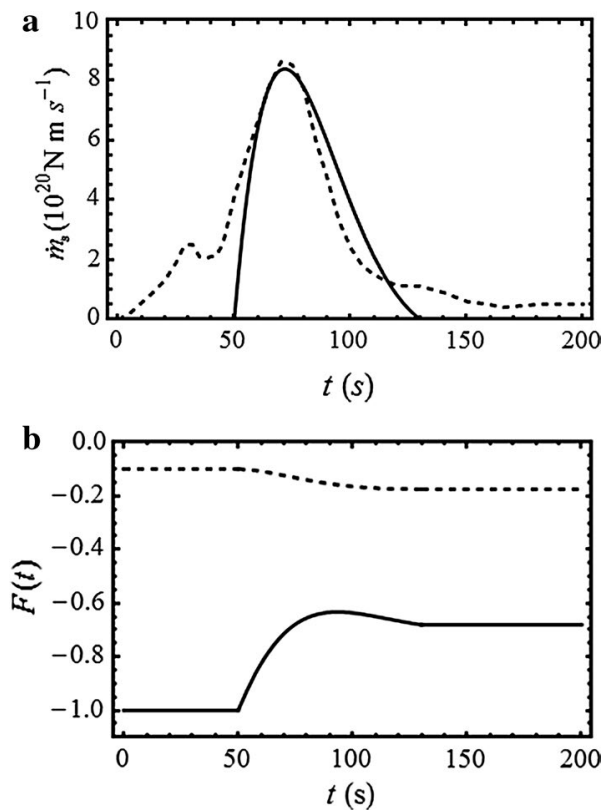

Fig. 8 Coseismic phase of the 2011 Tohoku-Oki earthquake. a Moment rate $\dot{m}_{\mathrm{s}}$ (solid) as a function of time, calculated according to (106), compared with the observed moment rate (dashed) reported by Wei et al. (2012). b Evolution of forces $F_{1}$ on the asperity (solid) and $F_{2}$ on the weak region (dashed), in units of the static friction $f_{s}$ of the asperity

region is $u_{\mathrm{a}}=0.23 u_{\mathrm{s}}$ or $3.5 \mathrm{~m}$. From (76), the geodetic moment associated with afterslip is $m_{\mathrm{a}}=0.23 m_{\mathrm{s}}$ or $8.3 \times 10^{21} \mathrm{~N} \mathrm{~m}$.

Let $s_{\mathrm{S}}$ be the coseismic ground displacement. According to Ozawa et al. (2011), a postseismic displacement $s_{\mathrm{a}}^{\prime}=0.09 s_{\mathrm{s}}$ was reached at a time $t_{\mathrm{a}}^{\prime}=15$ days after the seismic event. We can ascribe $s_{\mathrm{a}}^{\prime}$ entirely to afterslip, because viscoelastic relaxation takes place over much longer times. With a viscosity equal to $10^{19} \mathrm{~Pa} \mathrm{~s}$ (Wang et al. 2012; Sun et al. 2014), the Maxwell time is $\theta^{\prime}=8$ a. By means of (101) and taking into account that surface displacement is proportional to fault slip, we find $\theta \simeq 30$ days. Hence, $\theta^{\prime} \gg \theta$, as anticipated.

The surface displacement generated by afterslip is shown as a function of time in Fig. 9. The curve is consistent with data from Diao et al. (2013) and Silverii et al. (2014), according to whom postseismic ground displacement reached the value $\bar{s}_{\mathrm{a}}$ after a time from 120 to 150 days from the event. We conclude that afterslip reached the asymptotic value $u_{\mathrm{a}}$ after a time $t_{\mathrm{a}}$ of about four months. Further postseismic deformation should be ascribed to viscoelastic relaxation. Finally, by means of (80) and the relation

$$
T_{\mathrm{a}}=\frac{t_{\mathrm{a}}}{t_{\mathrm{s}}} T_{\mathrm{s}}
$$

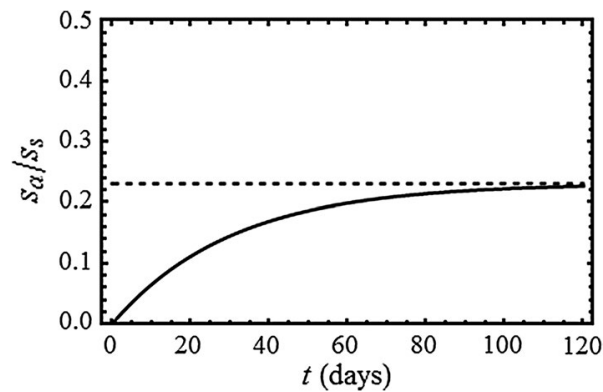

Fig. 9 Surface displacement generated by afterslip following the 2011 Tohoku-Oki earthquake, according to the model. The surface displacement is estimated over a time interval of 120 days. It is normalized to the coseismic surface displacement $s_{s}$

we find $\lambda \simeq 10^{5}$.

The ground displacement produced by afterslip has been calculated making use of Okada's (1985) formulae. The graphs of the horizontal and vertical displacement components are shown in Fig. 10. The direction and magnitude of the calculated displacement are broadly comparable with displacements obtained from GPS data over a time interval comparable with $t_{\mathrm{a}}$. For instance, Silverii et al. (2014) reported a maximum horizontal displacement of the order of $1 \mathrm{~m}$ at the eastern coasts of the Iwate/Miyagi prefectures of Japan and a maximum vertical displacement of about 20 $\mathrm{cm}$ in the same area. These figures are in good agreement with the results shown in Fig. 10, where the eastern coasts of the Iwate/Miyagi prefectures approximately correspond with the projection of the lower margin of the weak fault region on the Earth's surface.

Of course, the present model cannot reproduce the details of the Tohoku-Oki earthquake nor of any other seismic event, but its aim is rather to investigate the basic mechanical processes occurring on the fault surface and to enlighten the relationships between them.

\section{Conclusions}

We presented a model that describes in a unique frame both seismic and aseismic slip on a fault, taking into account the interaction between the two processes. This has been achieved by considering a fault containing two regions with different mechanical behaviours: a strong, velocity-weakening region (asperity) and a weak, velocity-strengthening region.

During the interseismic intervals, the asperity is locked, while the weak region is subject to a very slow creep. Consequently, the slip deficit of the asperity increases in time with the velocity of tectonic plates, while the slip deficit of the weak region increases much slower. The asperity accumulates stress and eventually releases it, producing an earthquake, when a frictional threshold is 


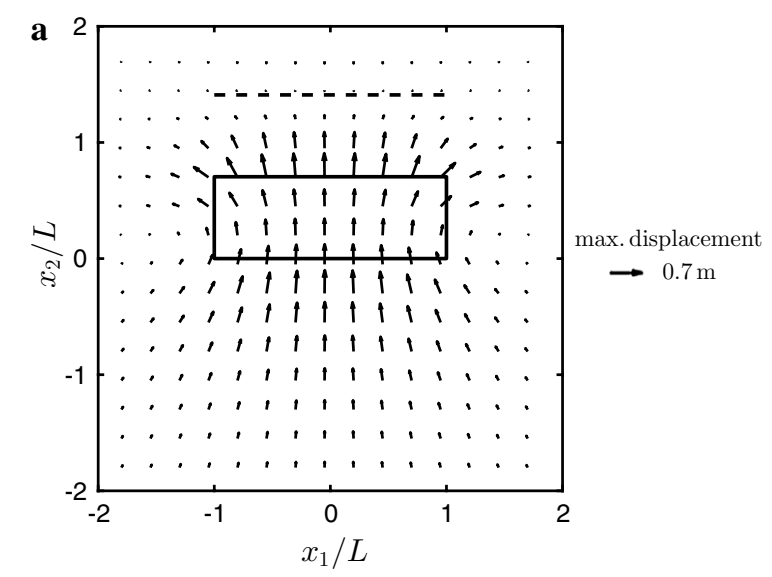

$u_{3}(\mathrm{~m})$

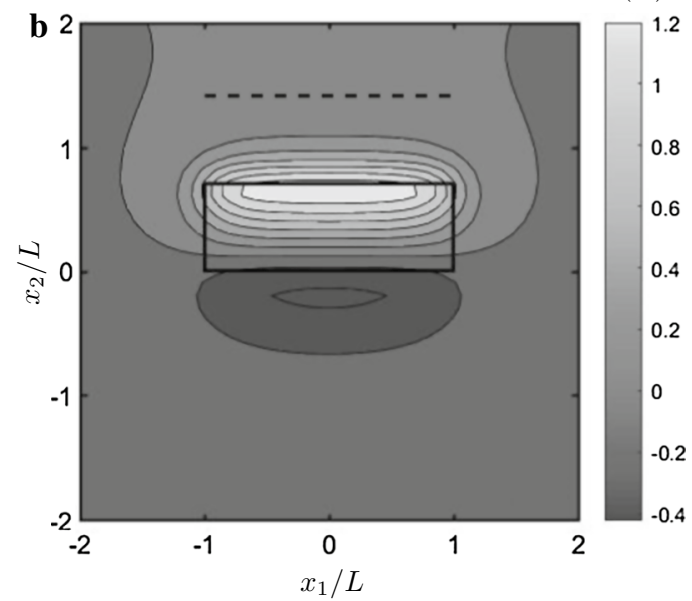

Fig. 10 Ground displacement produced by afterslip following the 2011 Tohoku-Oki earthquake, according to the model. a Horizontal component; $\mathbf{b}$ vertical component $u_{3}$. The rectangle is the projection of the weak fault region on the Earth's surface, and the dashed segment is the fault trace. The $x_{1}$ and $x_{2}$ axes are parallel to the strike direction of the fault and to the direction normal to strike, respectively. Distances are measured in units of the half-side of the fault along the strike direction, namely $L=200 \mathrm{~km}$

exceeded. As a consequence of coseismic stress imposed by the asperity failure, the weak region is then subject to aseismic slip (afterslip).

The evolution equations of the system have been solved analytically for the interseismic intervals, the asperity slip and the afterslip in the weak region. The amount of afterslip is found to be proportional to the seismic slip of the asperity, in agreement with observations. The proportionality factor depends on the geometry of the fault and on the velocity of tectonic motion.

The model shows that afterslip is a natural consequence of seismic slip in a fault containing a velocitystrengthening region. Afterslip may have any duration, according to the intensity of velocity strengthening, thus accounting for the wide range of observed durations. According to the model, afterslip approaches an asymptotic value as time increases. We have shown that the higher rate that is often observed in postseismic deformation may be due to the superposition of the effects of afterslip and viscoelastic relaxation in the asthenosphere.

The model has been applied to the fault of the 2011 Tohoku-Oki earthquake. On the basis of data, the fault has been considered as made of a single large asperity, extending from the Japan trench to about $50 \mathrm{~km}$ of depth, and a weak region located downdip of the asperity to a depth of about $100 \mathrm{~km}$. With the appropriate values of the model parameters, the dominant part of the seismic moment rate has been reproduced. The stress transfer from the slipping asperity produces a substantial increase of shear stress on the weak region, which is responsible for afterslip. The results suggest that the first four months after the event were dominated by afterslip, while the subsequent postseismic deformation was probably due to viscoelastic relaxation in the asthenosphere. Of course, the model presents a simplified description of real fault dynamics. It necessarily disregards complicated physical processes that may be dealt with via a numerical approach. However, a discrete model as the one we presented offers an alternative insight on the essential dynamics of the seismic source in an analytical framework.

\section{Authors' contributions}

MD developed the model, solved the equations and wrote a preliminary version of the paper; EL checked the solutions and gave further contributions to the text and to data collection. Both authors discussed extensively the results. Both authors read and approved the final manuscript.

\section{Acknowlegements}

The authors are grateful to the editor Ryosuke Ando, to Suguru Yabe and to anonymous referees for useful comments on the first version of the paper.

\section{Competing interests}

The authors declare that they have no competing interests.

\section{Availability of data and materials}

All data and results supporting this work were gathered from the papers listed in References and are freely available to the public.

\section{Consent for publication}

Not applicable.

Ethics approval and consent to participate

Not applicable.

\section{Funding}

Not applicable.

\section{Publisher's Note}

Springer Nature remains neutral with regard to jurisdictional claims in published maps and institutional affiliations. 
Received: 21 April 2017 Accepted: 13 October 2017 Published online: 23 October 2017

\section{References}

Abe Y, Kato N (2013) Complex earthquake cycle simulations using a twodegree-of-freedom spring-block model with a rate-and state-friction law. Pure Appl Geophys 170(5):745-765

Amendola A, Dragoni M (2013) Dynamics of a two-fault system with viscoelastic coupling. Nonlinear Process Geophys 20:1-10. doi:10.5194/ npg-20-1-2013

Barbot S, Fialko Y, Bock Y (2009) Postseismic deformation due to the $M_{w} 6.0$ 2004 Parkfield earthquake: stress-driven creep on a fault with spatially variable rate-and-state friction parameters. J Geophys Res 114:B07405. doi:10.1029/2008JB005748

Belardinelli ME, Bonafede M (1995) Post-seismic stress evolution for a strikeslip fault in the presence of a viscoelastic asthenosphere. Geophys J Int 123:744-756. doi:10.1111/j.1365-246X.1995.tb06887.x

Bletery Q, Sladen A, Delouis B, Vallée M, Nocquet J-M, Rolland L, Jiang J (2014) A detailed source model for the $M_{w} 9.0$ Tohoku-Oki earthquake reconciling geodesy, seismology, and tsunami records. J Geophys Res Solid Earth 119:7636-7653. doi:10.1002/2014JB011261

Diao FQ, Xiong X, Wang RJ, Zheng Y, Walter TR, Weng HH, Li J (2013) Overlapping post-seismic deformation processes: afterslip and viscoelastic relaxation following the 2011 Mw 9.0 Tohoku (Japan) earthquake. Geophys J Int 196(1):218-229. doi:10.1093/gji/ggt376

Dieterich J (1994) A constitutive law for rate of earthquake production and its application to earthquake clustering. J Geophys Res 99:2601-2618. doi:10.1029/93JB02581

Dragoni M, Lorenzano E (2015) Stress states and moment rates of a twoasperity fault in the presence of viscoelastic relaxation. Nonlinear Process Geophys 22:349-359. doi:10.5194/npg-22-349-2015

Dragoni M, Lorenzano E (2016) Conditions for the occurrence of seismic sequences in a fault system. Nonlinear Process Geophys 23:419-433. doi:10.5194/npg-23-419-2016

Dragoni M, Piombo A (2015) Effect of stress perturbations on the dynamics of a complex fault. Pure Appl Geophys 172:2571-2583. doi:10.1007/ s00024-015-1046-5

Dragoni M, Santini S (2015) A two-asperity fault model with wave radiation. Phys Earth Planet Inter 248:83-93. doi:10.1016/j.pepi.2015.08.001

Dragoni M, Tallarico A (1992) Interaction between seismic and aseismic slip along a transcurrent fault: a model for seismic sequences. Phys Earth Planet Inter 72:49-57. doi:10.1016/0031-9201(92)90048-Z

Dragoni M, Tallarico A (2016) Complex events in a fault model with interacting asperities. Phys Earth Planet Inter 257:115-127. doi:10.1016/j. pepi.2016.05.014

Dublanchet P, Bernard P, Favreau P (2013) Interactions and triggering in a 3-D rate-and-state asperity model. J Geophys Res Solid Earth 118(5):2225-2245

Heki K, Miyazaki S, Tsuji H (1997) Silent fault slip following an intraplate thrust earthquake at the Japan Trench. Nature 386:595-598. doi:10.1038/386595a0

Ide S, Baltay A, Beroza GC (2011) Shallow dynamic overshoot and energetic deep rupture in the 2011 Mw 9.0 Tohoku-Oki earthquake. Science 332:1426-1429. doi:10.1126/science.1207020

linuma T, Hino R, Kido M, Inazu D, Osada Y, Ito Y, Ohzono M, Tsushima H, Suzuki S, Fujimoto H, Miura S (2012) Coseismic slip distribution of the 2011 off the Pacific Coast of Tohoku Earthquake (M9.0) refined by means of seafloor geodetic data. J Geophys Res. doi:10.1029/2012JB009186

Jaeger JC, Cook NGW (1976) Fundamentals of rock mechanics. Chapman \& Hall, London

Johnson LR (2010) An earthquake model with interacting asperities. Geophys J Int 182:1339-1373. doi:10.1111/j.1365-246X.2010.04680.x

Kanamori H (2001) Energy budget of earthquakes and seismic efficiency, in earthquake thermodynamics and phase transformations in the earth's interior. Academic Press, Cambridge, pp 293-305
Kato N (2004) Interaction of slip on asperities: numerical simulation of seismic cycles on a two-dimensional planar fault with nonuniform frictional property. J Geophys Res Solid Earth 109(B12):B12306-1

Kato N (2014) Deterministic chaos in a simulated sequence of slip events on a single isolated asperity. Geophys J Int 198(2):727-736. doi:10.1093/gji/ ggu157

Kato T, ElFiky GS, Oware EN, Miyazaki S (1998) Crustal strains in the Japanese islands as deduced from dense GPS array. Geophys Res Lett 25(18):34453448. doi:10.1029/98GL02693

Kenner S, Segall P (2000) Postseismic deformation following the 1906 San Francisco earthquake. J Geophys Res 105(B6):13195-13209. doi:10.1029/ 2000JB900076

Lay T, Kanamori H, Ammon CJ, Koper KD, Hutko AR, Ye L, Yue H, Rushing TM (2012) Depth-varying rupture properties of subduction zone megathrust faults. J Geophys Res 117:B04311. doi:10.1029/2011JB009133

Maercklin N, Festa G, Colombelli S, Zollo A (2012) Twin ruptures grew to build up the giant 2011 Tohoku, Japan, earthquake. Sci Rep 2:709. doi:10.1038/ srep00709

Marone C, Scholz CH, Bilham R (1991) On the mechanics of earthquake afterslip. J Geophys Res 96(B5):8441-8452

Nason R, Weertman J (1973) A dislocation theory analysis of fault creep events. J Geophys Res 78:7745-7751. doi:10.1029/JB078i032p07745

Noda H, Lapusta N (2013) Stable creeping fault segments can become destructive as a result of dynamic weakening. Nature 493:518-521. doi:10.1038/nature11703

Okada Y (1985) Surface deformation due to shear and tensile faults in a halfspace. Bull Seismol Soc Am 75:1135-1154

Ozawa S, Nishimura T, Suito H, Kobayashi T, Tobita M, Imakiire T (2011) Coseismic and postseismic slip of the 2011 magnitude-9 Tohoku-Oki earthquake. Nature 475:373-377. doi:10.1038/nature10227

Rice JR (1993) Spatio-temporal complexity of slip on a fault. J Geophys Res 98:9885-9907. doi:10.1029/93JB00191

Ruff $\sqcup$ (1992) Asperity distributions and large earthquake occurrence in subduction zones. Tectonophysics 211:61-83. doi:10.1016/0040-1951(92)90051-7

Ruina A (1983) Slip instability and state variable friction laws. J Geophys Res 88:10359-10370. doi:10.1029/JB088iB12p10359

Scholz CH (1990) The mechanics of earthquakes and faulting. Cambridge University Press, Cambridge

Scholz CH (1998) Earthquakes and friction laws. Nature 391:37-42 doi:10.1038/34097

Silverii F, Cheloni D, D'Agostino N, Selvaggi G, Boschi E (2014) Post-seismic slip of the 2011 Tohoku-Oki earthquake from GPS observations: implications for depth-dependent properties of subduction megathrusts. J Int Geophys. doi:10.1093/gji/ggu149

Simons M, Minson SE, Sladen A, Ortega F, Jiang J, Owen SE, Meng L, Ampuero J-P, Wei S, Chu R, Helmberger DV, Kanamori H, Hetland E, Moore AW, Webb FH (2011) The 2011 magnitude 9.0 Tohoku-Oki earthquake: Mosaicking the megathrust from seconds to centuries. Science 332:1421-1425. doi:10.1126/science 1206731

Sun T, Wang K, linuma T, Hino R, He J, Fujimoto $H$, Kido M, Osada Y, Miura S, Ohta Y, Hu Y (2014) Prevalence of viscoelastic relaxation after the 2011 Tohoku-Oki earthquake. Nature 514:84-87. doi:10.1038/ nature13778

Tallarico A, Dragoni M, Zito G (2002) Interaction between shallow and subcrustal dislocations on a normal fault. Phys Earth Planet Inter 129:67-82. doi:10.1016/S0031-9201(01)00211-4

Turcotte DL (1997) Fractals and chaos in geology and geophysics, 2nd edn. Cambridge University Press, Cambridge

Turcotte DL, Schubert G (2002) Geodynamics, 2nd edn. Cambridge University Press, Cambridge

Wang K, Hu Y, He J (2012) Deformation cycles of subduction earthquakes in a viscoelastic Earth. Nature 484:327-332. doi:10.1038/nature11032

Wei S, Graves R, Helmberger D, Avouac J-P, Jiang J (2012) Sources of shaking and flooding during the Tohoku-Oki earthquake: a mixture of rupture styles. Earth Planet Sci Lett 333-334:91-100. doi:10.1016/j. epsl.2012.04.006

Yabe S, Ide S (2017) Slip-behavior transitions of a heterogeneous linear fault. J Geophys Res 122(1):387-410. doi:10.1002/2016JB013132 
Yagi Y, Kikuchi M (2002) Partitioning between seismogenic and aseismic slip as highlighted from slow slip events in Japan. AGU Fall Meeting Abstracts

Yamagiwa S, Miyazaki S, Hirahara K, Fukahata Y (2015) Afterslip and viscoelastic relaxation following the 2011 Tohoku-Oki earthquake $\left(M_{w} 9.0\right)$ inferred from inland GPS and seafloor GPS/acoustic data. Geophys Res Lett 42:66-73. doi:10.1002/2014GL061735

Yoshida S, Kato N (2003) Episodic aseismic slip in a two-degree-of-freedom block-spring model. Geophys Res Lett. doi:10.1029/2003GL017439

\section{Submit your manuscript to a SpringerOpen ${ }^{\odot}$} journal and benefit from:

- Convenient online submission

- Rigorous peer review

- Open access: articles freely available online

- High visibility within the field

- Retaining the copyright to your article

Submit your next manuscript at $\boldsymbol{\nabla}$ springeropen.com 